\title{
General dental practitioners' knowledge of polymerisation of resin-based composite restorations and light curing unit technology
}

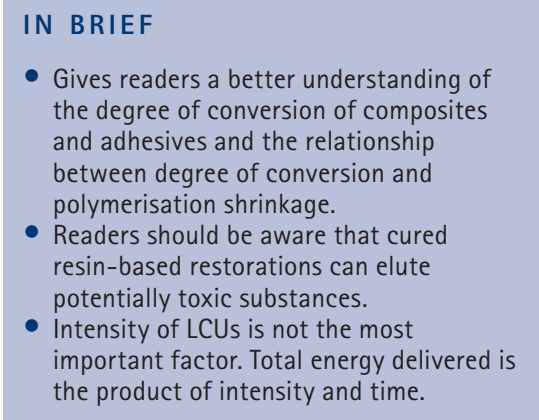

\author{
A. Santini ${ }^{1}$ and S. Turner ${ }^{2}$
}

Objective Clinical successful use of resin-based composite restorations (RBCs) depends on knowledge of material and light curing unit (LCU) related factors. The purpose of this study was to evaluate general dental practitioners' knowledge of polymerisation of RBCs and LCU technology. Methods Members of the Active Research Group of the Faculty of General Dental Practice (UK) in England, Scotland and Wales engaged in primary dental care were sent a letter introducing the study and asking for their cooperation, followed by an email containing a link to the online survey questionnaire, hosted on Surveymonkey.com. The questionnaire enquired about current LCUs, and asked a series of questions on material science. Results Sixty-six percent of the 274 members contacted responded. Fifty-seven percent used LED units, 25\% quartz tungsten halogen (OTH), and 1\% plasma arc (missing: 17\%). Thirty percent reported having access to a radiometer. Appropriate responses regarding the degree of conversion of composite and adhesive materials were given by $32 \%$ and $23 \%$ respectively, and 22\% agreed that LED and QTH LCUs had comparable efficiency in polymerising composites. Thirty-three percent were aware that RBCs eluted substances that may have adverse local or systemic consequences. Fifty-eight percent stated that if polymerisation of RBC is slowed down, polymerisation stress will be lower, and $43 \%$ said that polymerisation shrinkage will be reduced if the degree of conversion is reduced. Knowledge (measured by appropriate responses to these questions) was not related to years since qualification ( $r=-0.05, n=168, p=0.53)$. Conclusion The study suggests that dentists' knowledge of curing RBC restorations and LCUs is poor. This indicates that there is a need for training and guidance in this aspect of primary dental care.

\section{INTRODUCTION}

Major changes in light-curing units (LCUs) and curing modes have occurred concurrently with resin-based composite material $(\mathrm{RBC})$ and dentine bonding agent (DBA) development. ${ }^{1-3}$ Moreover the type of LCU and curing mode are known to impact on the polymerisation kinetics and associated stresses, micro-hardness, depth of cure $^{4-6}$ and the degree of conversion of RBCs. ${ }^{7}$ Monomer conversion to polymer is an important determinant of the physico-mechanical properties of the resultant polymer $^{8}$ and RBCs that receive inadequate amounts of energy from a LCU, or energy

\footnotetext{
"The Faculty of General Dental Practice, The Royal College of Surgeons of England, Lincoln's Inn Fields, London WC2A 3PE; ${ }^{2}$ Edinburgh Postgraduate Dental Institute, The University of Edinburgh, Lauriston Buildings, Lauriston Place, Edinburgh, EH3 9HA

*Correspondence to: Dr Ario Santini

Email:ariosantini@hotmail.com
}

Online article number E13

Refereed Paper - accepted 21 July 2011

DOI: 10.1038/sj.bdj.2011.768

${ }^{\circledR}$ British Dental Journal 2011; 211: E13 at the wrong wavelengths, are inadequately polymerised. ${ }^{9,10}$ Conversion is seldom complete $^{11-14}$ and lower conversion results in reduced physical properties, ${ }^{16-20}$ reduced bond strengths, ${ }^{20}$ decreased marginal integrity and increased wear, ${ }^{21,22}$ higher permeability, ${ }^{23}$ more water sorption ${ }^{24}$ and more leaching out of uncured monomers..$^{25,26}$

When using RBCs and adhesive materials, it is essential for the dental professional to have a thorough knowledge of material properties and LCU technology and to establish an appropriate clinical approach that will protect healthy tissues, while meeting the patient's aesthetic expectations. ${ }^{22}$ In 2005, 116 million resin restorations were placed in the USA. ${ }^{27}$ Most studies report that $\mathrm{RBC}$ restorations are not lasting as long as they could, ${ }^{28-31}$ although there are reports that the longevity of these restorations can equal amalgam. ${ }^{32,33}$

One reason for sub-optimal restorations may be inadequacy of performance and maintenance of LCUs in use in primary care. The relatively few studies which have examined this aspect of dentistry have indicated considerable shortcomings. An early study in the UK reported that only one-fifth of the participating practices had some means of checking LCU effectiveness. ${ }^{34}$ A second UK study found that $28 \%$ of LCUs examined had inadequate light output, and 48\% were damaged or repaired. The authors concluded that practitioners should address practical aspects of their increasing reliance on light units. ${ }^{35}$

Two Canadian studies based on private dental offices found that units older than three years had significantly lower output intensities, and recommended that dentists regularly monitor the intensity of their LCUs to ensure quality RBC restorations. ${ }^{36,37}$

In addition, dentists' practice and knowledge may be inadequate. In a review of factors affecting the performance of LCUs, Strydom ${ }^{38}$ cites evidence that dentists tend to cure for too short a period, possibly because they are unaware of the 


\begin{tabular}{|l|l|}
\hline \multicolumn{2}{|l|}{ Table 1 Type of LCU used $(n=181)$} \\
\hline LCU type & $\%(n)$ \\
\hline LED & $103(56.9 \%)$ \\
\hline OTH & $46(25.4 \%)$ \\
\hline Plasma arc & $2(1.1 \%)$ \\
\hline Don't know & $27(14.9 \%)$ \\
\hline Missing & $3(1.7 \%)$ \\
\hline
\end{tabular}

importance of adequate light intensity and of factors that may reduce intensity and lower the degree of polymerisation. The author suggests several clinical recommendations to provide general dental practitioners (GDPs) with information on how to optimise the degree of cure. In spite of the general consensus that it is essential for GDPs to understand the many factors which influence the polymerisation of light activated RBCs and the choice of LCUs, ${ }^{39-41}$ a recent study concluded that if the reported findings were representative of the dental profession as a whole, dental practitioners may not be up-to-date in their knowledge of dental material science. ${ }^{42}$

\section{AIMS}

The aim of the present study was to assess the knowledge of polymerisation of RBC materials and light curing technology of dentists working mainly in general dental practice.

\section{MATERIALS AND METHODS}

The study was conducted under the aegis of the FGDP(UK) in collaboration with the Edinburgh Postgraduate Dental Institute, The University of Edinburgh, which administered and analysed the survey. Members of the Faculty Active Research Group in England, Wales and Scotland who were actively engaged in primary dental care, were sent a letter introducing the study and asking for their cooperation followed by an email containing a link to the online survey questionnaire, hosted on Surveymonkey.com. Two further reminders were sent. Responses were analysed using SPSS v17.

The questionnaire covered four topics: 1. Description of their LCU and related

Table 2 Reported LCU features and satisfaction with unit

\begin{tabular}{|c|c|c|c|c|}
\hline & Very satisfied & $<$ very satisfied & $\begin{array}{l}\text { Chi-square/Fisher's } \\
\text { exact test } p \text { value }\end{array}$ \\
\hline Type & $\begin{array}{l}\text { LED } \\
\text { QTH } \\
\text { Missing: } 34\end{array}$ & $\begin{array}{l}55(53.4 \%) \\
15(34.1 \%)\end{array}$ & $\begin{array}{l}48(46.6 \%) \\
29(65.9 \%)\end{array}$ & 0.047 \\
\hline Start mode & $\begin{array}{l}\text { 'Soft start' or similar } \\
\text { Conventional start mode } \\
\text { Missing: } 57\end{array}$ & $\begin{array}{l}25(56.1 \%) \\
32(47.8 \%)\end{array}$ & $\begin{array}{l}32(43.9 \%) \\
35(52.2 \%)\end{array}$ & 0.053 \\
\hline Intensity & $\begin{array}{l}>1000 \mathrm{~mW} / \mathrm{cm}^{2} \\
\text { c. } 700 \mathrm{~mW} / \mathrm{cm}^{2} \\
\text { c. } 450 \mathrm{~mW} / \mathrm{cm}^{2} \\
\text { Missing: } 104\end{array}$ & $\begin{array}{l}22(73.3 \%) \\
11(42.3 \%) \\
4(19.0 \%)\end{array}$ & $\begin{array}{c}8(26.7 \%) \\
15(57.7 \%) \\
17(81.0 \%)\end{array}$ & 0.001 \\
\hline
\end{tabular}

equipment. Whenever possible the details of LCU manufacturer and model provided by respondents were cross-referenced with the reported LCU features in order to verify the accuracy of the reports. When insufficient verifying information was given, it has been assumed that the features were described accurately. This implies that any identified error may underestimate the actual level of unfamiliarity with this equipment

2. Level of satisfaction with their LCU (one 5-point rating scale, where 1 = very satisfied, 2 = quite satisfied, 3 = neither, 4 = quite dissatisfied, and 5 = very dissatisfied)

3. Understanding of material sciences. Six questions covering understanding of material sciences were devised to permit comparisons of pairs of related questions: ie two were on the degree of conversion, two on stress and shinkage during polymerisation, and two on the nature of polymerisation. A seventh question asked about the relative efficiency of quartz tungsten halogen (QTH) and light emitting diode (LED) LCUs. One question asked about using different curing times for adhesive and composite materials. Respondents' knowledge of material science was summarised by a knowledge score (sum of appropriate answers to the eight questions on material science), with a range of 0 to 8 . This score was used to test the premise that members with longer clinical experience may be more knowledgable in material science

4. Professional background and current employment.

\section{Statistical analysis}

Fisher's exact test was used to identify whether certain features of LCUs were related to others: ie were respondents with a LCU with an intensity $>1000 \mathrm{~mW} / \mathrm{cm}^{2}$ more likely to also have a radiometer? Chisquare and Fisher's exact test were used to investigate whether such features were associated with respondents' satisfaction with their LCU. McNemar's Chi-square test was used to compare the proportion of appropriate responses within each pair of related questions on knowledge of material science of the same individual. The Pearson correlation coefficient was used to test for an association between material science knowledge scores and clinical experience (years since qualification).

\section{RESULTS}

Of the approximately 5,000 members of the FGDP(UK), 274 had enrolled in the Faculty Active Research Group by 2009. All these 274 were contacted: 66\% (181) responded. One hundred and fifteen (70.1\%) were male and 49 (29.9\%) female (missing: 17); 159 (92.4\%) worked in the general dental service, 13 (7.6\%) in hospital, and five $(2.9 \%)$ in the salaried service. Three (1.7\%) described themselves as specialist orthodontists, and three worked for the army. There was some split-working across these groups. Mean years since qualification was 18.7 years (SD: 11.4); 50 (29.8\%) were qualified less than 10 years, $36(21.4 \%) 10$ years up to 20, and $168(48.8 \%) 20$ years or more (missing: 13).

\section{LCU equipment in use}

Over 40 named units from 32 different LCU manufacturers were cited. Fifty-seven percent of respondents gave their LCU type as 


\section{Table 3 Understanding of material science}

\begin{tabular}{|c|c|c|c|c|c|}
\hline \multirow{2}{*}{$\begin{array}{l}\text { 1. All other factors being equal, would you consider a } \\
\text { QTH light, operating at } 450 \mathrm{~mW} / \mathrm{Cm}^{2} \text { for } 20 \text { secs to be } \\
\text { more, less or equally efficient at polymerising compos- } \\
\text { ite materials compared with an LED light operating at } \\
1000 \mathrm{~mW} / \mathrm{cm}^{2} \text { at } 10 \text { seconds? }\end{array}$} & More efficient & Less efficient & Equally efficient & Don't Know & Missing \\
\hline & $11(6.1 \%)$ & 48 (26.5\%) & 39 (21.5\%) & 72 (39.8\%) & 11 (6.1\%) \\
\hline \multirow{2}{*}{$\begin{array}{l}\text { 2. Normally, following manufacturers' instructions, } \\
\text { the degree of conversion of composite materials is: }\end{array}$} & About $100 \%$ & About $75 \%$ & About $50 \%$ & Don't Know & Missing \\
\hline & $52(29.5 \%)$ & 57 (32.4\%) & $2(1.1 \%)$ & $60(33.1 \%)$ & $10(5.6 \%)$ \\
\hline \multirow{2}{*}{$\begin{array}{l}\text { 3. Normally, following manufacturers' instructions, } \\
\text { the degree of conversion of adhesives is: }\end{array}$} & About $100 \%$ & About $75 \%$ & About $50 \%$ & Don't Know & Missing \\
\hline & $62(35.2 \%)$ & $40(22.7 \%)$ & $5(2.8 \%)$ & $62(39.5 \%)$ & $12(6.7 \%)$ \\
\hline & & Agree & Disagree & Don't Know & Missing \\
\hline \multicolumn{2}{|c|}{$\begin{array}{l}\text { 4. When curing composite materials, monomers are converted to polymers } \\
\text { by light or chemical activation. }\end{array}$} & $132(72.9 \%)$ & 10 (5.7\%) & $30(16.6 \%)$ & $9(5.0 \%)$ \\
\hline \multicolumn{2}{|c|}{$\begin{array}{l}\text { 5. All other factors being equal, if polymerisation of composite materials is } \\
\text { slowed down, polymerisation stress will be lower. }\end{array}$} & $105(58.0 \%)$ & $25(13.8 \%)$ & 41 (22.7\%) & $10(5.6 \%)$ \\
\hline \multicolumn{2}{|c|}{$\begin{array}{l}\text { 6. All other factors being equal, if the degree of conversion is reduced, } \\
\text { polymerisation shrinkage will be reduced. }\end{array}$} & 78 (43.1\%) & $29(16.0 \%)$ & $64(35.4 \%)$ & $10(5.6 \%)$ \\
\hline \multicolumn{2}{|c|}{$\begin{array}{l}\text { 7. Cured composite materials elute substances that may have adverse local } \\
\text { or systemic consequences. }\end{array}$} & $60(33.1 \%)$ & 45 (24.9\%) & 67 (37.0\%) & $9(5.0 \%)$ \\
\hline \multicolumn{2}{|l|}{ 8. Use of different curing times for adhesives and composites. } & $128(70.7 \%)$ & 41 (22.7\%) & $3(1.7 \%)$ & $9(5.0 \%)$ \\
\hline
\end{tabular}

LED, 25\% as QTH, and 2\% as plasma arc. Seventeen percent did not know or did not respond (Table 1).

Respondents were asked about certain features of their equipment: 31.5\% (57) reported having a 'soft start' or similar LCU (SS LCU), 16.6\% (30) reported having a LCU of intensity $>1000 \mathrm{~mW} / \mathrm{cm}^{2}$ (HI LCU), and 29.8\% (54) reported access to a radiometer (although only 17 reported using the radiometer at least once a year). These responses were associated, in that $49.1 \%$ (28) of those with a SS LCU also reported having a radiometer, compared with 23.9\% (16) of those with standard start LCU (Fisher's exact test $\mathrm{p}=0.005$ : missing 57). Equally, dentists who reported using a SS LCU were more likely to report having a HI LCU (57.1\% (16) cf 30.3\% (10)) (Fisher's exact test $\mathrm{p}=0.042$ : missing 120), as were those with a radiometer (59.3\% (16) cf 28.6\% (12)) (Fisher's exact test $p=0.014$ : missing 112 ). The high level of missing data reflects the numbers who reported not knowing about these features of their LCUs.

Where possible descriptions of unit type, start mode and intensity were verified by reference to reported make and model. When insufficient verifying information was given, it has been assumed that the features were described accurately. On this basis, 83.4\% (151) correctly reported LCU type (LED or QTH), and 57.5\% (104) and

\section{Table 4 Approximate degree of conversion of composites and adhesives}

\begin{tabular}{|c|c|c|c|c|}
\hline & & \multicolumn{3}{|c|}{$\begin{array}{l}\text { 02. Normally, following manufacturers' instructions, } \\
\text { the degree of conversion of composite materials is: }\end{array}$} \\
\hline & & $<75 \%$ & All other answers & Total \\
\hline \multirow{3}{*}{$\begin{array}{l}\text { 03. Normally, following } \\
\text { manufacturers' instructions, } \\
\text { the degree of conversion of } \\
\text { adhesives is: }\end{array}$} & $<75 \%$ & 32 & 8 & $40(22.7 \%)$ \\
\hline & $\begin{array}{l}\text { All other } \\
\text { answers }\end{array}$ & 25 & 111 & 136 (77.3\%) \\
\hline & Total & $57(32.4 \%)$ & $119(67.6 \%)$ & $176(100.0 \%)$ \\
\hline
\end{tabular}

Table 5 Stress and shrinkage during polymerisation

\begin{tabular}{|c|c|c|c|c|}
\hline & & \multicolumn{3}{|c|}{$\begin{array}{l}\text { Q5. All other factors being equal, if polymerisation of } \\
\text { composite materials is slowed down, polymerisation } \\
\text { stress will be lower. }\end{array}$} \\
\hline & & Agree & All other answers & Total \\
\hline \multirow{3}{*}{$\begin{array}{l}\text { 06. All other factors } \\
\text { being equal, if the degree } \\
\text { of conversion is reduced, } \\
\text { polymerisation shrinkage } \\
\text { will be reduced. }\end{array}$} & Agree & 58 & 20 & 78 (44.3\%) \\
\hline & $\begin{array}{l}\text { All other } \\
\text { answers }\end{array}$ & 47 & 51 & 98 (55.7\%) \\
\hline & Total & $105(55.7 \%)$ & 71 (40.3\%) & 176 (100.0\%) \\
\hline
\end{tabular}

$37.5 \%$ (68) respectively correctly described start-up mode and operating intensity.

\section{Satisfaction with unit}

Rating of satisfaction indicated a generally high level of satisfaction: $43.5 \%$ (77) said they were very satisfied, $41.8 \%$ (74) quite satisfied, 7.3\% (13) neither satisfied or dissatisfied, 6.2\% (11) quite dissatisfied and $1.1 \%(2)$ very dissatisfied (missing:
4). A high level of satisfaction (ie as a dichotomous variable: 1 = very satisfied, $0=$ all other responses) was associated with use of LED units (Fisher's exact test: $\mathrm{p}=0.047$ ) and higher intensity units (Chisquare $=15.10 ; p=0.047)$ (Table 2$)$.

\section{Understanding of material science}

Table 3 shows responses to eight questions investigating the understanding of 
material science among respondents. The most appropriate responses are shown in bold.

Table 4 shows the comparisons of the responses on the degree of conversion of composites and adhesives. Respondents were more likely to give an appropriate response (ie '<75\%') regarding conversion of composites than regarding conversion of adhesives (McNemar's test $\mathrm{p}=0.005$ ).

Table 5 compares responses regarding stress and shinkage during polymerisation. Respondents were more likely to give an appropriate response (ie 'agree') regarding lowering of stress during polymerisation than for reduction of shrinkage (McNemar's test $\mathrm{p}=0.001$ ).

Table 6 shows that respondents were more likely to give an appropriate response (ie 'agree') regarding the conversion of monomers to polymers than for the possible elution of hazardous substances (McNemar's test $\mathrm{p}=0.001$ ).

Knowledge of material science scores (sum of appropriate answers as shown in Table 3) had a mean of 3.69 (SD: 1.63; median: $4 ; \mathrm{n}=172$ ) out of a maximum of 8. Four dentists scored 0 , and nine had missing scores (all eight questions omitted). Knowledge scores were not related to years since qualification $(\mathrm{r}=-0.05$, $\mathrm{n}=168, \mathrm{p}=0.53$ ).

\section{DISCUSSION}

The survey population was all FGDP(UK) members self-enrolled in the Faculty Active Research Group, and therefore are unlikely to be representative either of the Faculty membership as a whole or of general dental practitioners. The survey response rate of $66 \%$ is considered to be adequate, given the generally lower response rates for online compared with mail-based surveys. ${ }^{43}$ One reason for non-response may be that some dentists felt less confident or knowledgeable about the subject matter of the study, and so decided against responding. It is possible therefore that the results of the study overstate dentists' level of knowledge of their LCU or the relevant aspects of material science. Faculty membership data suggests the study respondents are reasonably representative of the gender split of the wider membership, 38\% of whom are female.

On the subject of current equipment in use by respondents, LED LCUs are now a

\section{Table 6. Conversion of composites}

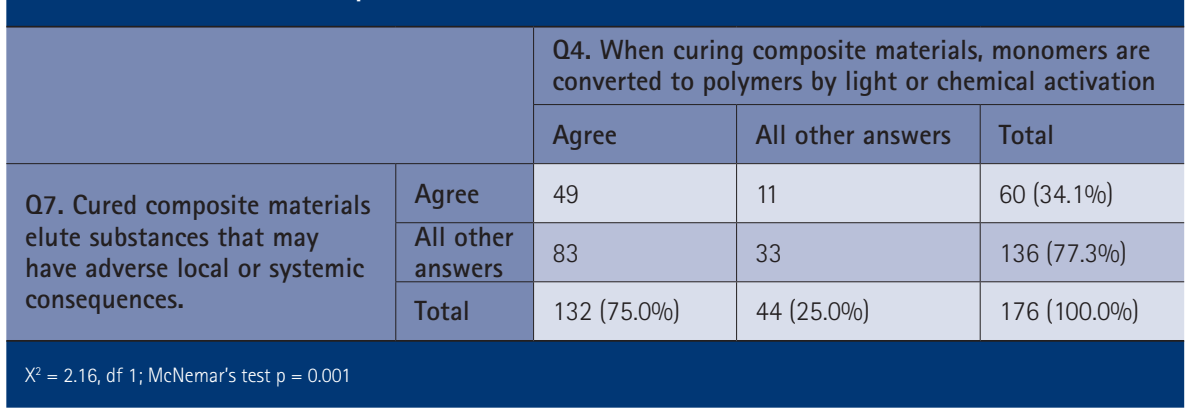

mainstay of many general practices. These units are an effective choice for replacing alternative light sources such as QTH and high-intensity QTH units. Many manufactures have taken their QTH LCU off the market. LED units are lightweight, typically portable, effective, and early reports suggest that in some circumstances they are able to out-perform other light types with respect to unit durability and curing performance. ${ }^{46-48}$ Results from the study suggest that LED LCU users are more satisfied with their units than QTH LCU users (Table 2). However, conventional LED LCUs with a single emission spectrum peaking at about $470 \mathrm{~nm}$, though compatible with the photoinitiator camphorquinone (CQ), are less effective, if at all, in initiating other photoinitiators such as Lucirin TPO and phenylpropanedion (PPD), whose absorption spectra are in the 390 to $430 \mathrm{~nm}$ range. These single peak LEDs may not adequately polymerise resin-based composites, which can lead to restoration failures and adverse pulpal responses to unpolymerised monomers. ${ }^{49}$

At least two manufacturers, IvoclarVivadent and Ultradent, have introduced polywave LEDs which have a spectral emission similar to QTH LCUs and therefore are compatible with photoinitiators other than CQ. The current study does not address these points but following from the lack of knowledge of LCUs and material science brought out in the study, these aspects of knowledge need to be investigated. Lack of understanding of this may lead to the purchase of inappropriate LCUs and, without intent, producing undercured resin-based restorations.

Fewer than 30\% reported that they had access to a radiometer, although it is possible that others were not aware that their LCU had a built in radiometer or that one was available in the surgery. This figure is little better than that reported by another UK study over 13 years earlier, when only one-fifth of practices had means of checking the efficiency of their LCU. ${ }^{36}$ However, several more recent studies ${ }^{41,50,51}$ have indicated that the use of radiometers in general dental practice can only provide approximate light intensity readings rather than an accurate calibration of the LCU. The implication of these studies is that radiometers may be useful monitoring devices when used to test intensity values against the value obtained when the LCU was new, as an indication of whether the original intensity is being maintained.

The study found that only a minority of respondents had appropriate understanding of the degree of conversion of composites and adhesives, the relationship between degree of conversion and polymerisation shrinkage, or that cured composite materials may elute potentially harmful substances. Such findings regarding the level of understanding of material science relevant to light curing of RBCs are in line with deficiencies reported in earlier studies. ${ }^{31,41,43}$ Several recent papers ${ }^{41,51,52}$ have reviewed the uses of LCUs, material properties and application techniques which minimise effects of polymerisation shrinkage and shrinkage stress when curing resin composite restorative materials. These reviews emphasise the severe problems resulting from polymerisation shrinkage and shrinkage stress, including the possibility of secondary caries, and argue that dental practitioners must know how to deal with such problems so that they can choose the material and procedure most likely to lead to clinical success.

The premise of an association between experience (years in practice) and knowledge of material science was not confirmed. This finding is supported by two earlier studies. Ueda ${ }^{53}$ compared the 
performance of dental students and experienced clinicians, and found no positive association between clinical experience and bonding effectiveness of composite cement to dentine. McFadzean ${ }^{42}$ in a survey of 138 dentists in Scotland regarding choice of resin-based composites and dentine-bonding agents, found no relationship between year of qualification and choice of material, which was largely determined by availability and ease of use. The authors called for further research into the level of understanding of material science by dental clinicians.

\section{CONCLUSION}

This study was conducted among members of the FGDP(UK), which represents 11\% of all dentists registered with the UK General Dental Council. Given the level of expertise implied by membership of the Faculty, it is reasonable to suppose that members' knowledge of light curing equipment and material science is better than that possessed by the dental profession as a whole. The consistent finding of lack of knowledge among respondents to the study is therefore likely to be strongly indicative of a more general need for training and guidance in this aspect of primary dental care.

1. Freiberg R S, Ferracane J L. Evaluation of cure, properties and wear resistance of Artglass denta composite. Am J Dent 1998; 11: 214-218.

2. Lohbauer U, Rahiotis $C$, Kramer N, Petschelt A, Eliades $\mathrm{G}$. The effect of different light-curing units on fatigue behaviour and degree of conversion of a resin composite. Dent Mater 2005; 21: 608-615.

3. Silikas N, Eliades G, Watts D C. Light intensity effects on resin-composite degree of conversion and shrinkage strain. Dent Mater 2000; 16: 292-296.

4. Rueggeberg FA, Caughman W F, Curtis J W Jr, Davis H C. Factors affecting cure at depths within light-activated resin composites. Am J Dent 1993; 6: 91-95.

5. Ferracane J L, Aday P, Matsumoto H, Marker V A Relationship between shade and depth of cure for light-activated dental composite resins. Dent Mater 1986: 2: 80-84.

6. Davidson-Kaban S S, Davidson C L, Feilzer A J, de Gee A J, Erdilek N. The effect of curing light variations on bulk curing and wall-to-wall quality of two types and various shades of resin composites. Dent Mater 1997; 13: 344-352.

7. Miletic V J, Santini A. Remaining unreacted methacrylate groups in resin-based composite with respect to sample preparation and storing conditions using micro-Raman spectroscopy. J Biomed Mater Res B Appl Biomater 2008; 87: 468-474.

8. Nomoto R, Asada M, McCabe J F, Hirano S. Light exposure required for optimum conversion of light activated resin systems. Dent Mater 2006; 22: 1135-1142.

9. Halvorson R H, Erickson R L, Davidson C L. Energy dependent polymerization of resin-based composite. Dent Mater 2002; 18: 463-469.

10. Bae J H, Cho B H, Kim J S et al. Adhesive layer properties as a determinant of dentin bond strength. J Biomed Mater Res B Appl Biomater 2005: 74: 822-828.
11. Enami N, Soderholm K J. How light irradiance and curing time affect monomer conversion in light-cured resin composites. Eur J Oral Sci 2003; 111: 536-542.

12. Santini A, Miletic V. Quantitative micro-Raman assessment of dentine demineralization, adhesive penetration, and degree of conversion of three dentine bonding systems. Eur J Oral Sci 2008; 116: 177-183.

13. Miletic V, Santini A. Micro-Raman assessment of the ratio of carbon-carbon double bonds of two adhesive systems cured with LED or halogen lightcuring units. J Adhes Dent 2010; 12: 461-467.

14. Witzel M F, Calheiros F C, Goncvalves F, Kawano $Y$, Braga R R. Influence of photoactivation method on conversion, mechanical properties, degradation in ethanol and contraction stress of resin based materials. J Dent 2005; 33: 773-779.

15. Correr A B, Sinhoreti M A, Correr-Sobrinho L, Tango $R$ N, Schneider L F, Consani S. Effect of the increase of energy density on Knoop hardness of dental composites light-cured by conventional $\mathrm{QTH}$, LED and xenon plasma arc. Braz Dent J 2005: 16: $218-224$.

16. Lohbauer U, Rahiotis $C$, Krämer N, Petschelt A, Eliades $\mathrm{G}$. The effect of different light-curing units on fatigue behaviour and degree of conversion of resin composite. Dent Mater 2005; 21: 608-615.

17. $X u X$, Sandras D A, Burgess J O. Shear bond strength with increasing light-guide distance from dentin. $J$ Esthet Restor Dent 2006; 8: 19-27.

18. Ferracane J L, Mitchem J C, Condon J R, Todd R. Wear and marginal breakdown of composites with various degrees of cure. J Dent Res 1997; 76: $1508-1516$

19. Kim S Y, Lee I B, Cho B H, Son H H, Um C M Curing effectiveness of a light emitting diode on dentin bonding agents. J Biomed Mater Res B Appl Biomater 2006; 77: 64-70.

20. Vandewalle K S, Ferracane J L, Hilton T J, Erickson $R L$, Sakaguchi R L. Effect of energy density on properties and marginal integrity of posterior resin composite restorations. Dent Mater 2004; 20: 96-106.

21. Caldas D B, de Almeida J B, Correr-Sobrinho L, Sinhoreti M A, Consani S. Influence of curing tip distance on resin composite Knoop hardness number, using three different light curing units. Oper Dent 2003; 28: 315-320.

22. Burke F J, McHugh S, Hall A C, Randall R C, Widstrom $\mathrm{E}$, Forss H. Amalgam and composite use in UK general dental practice in 2001. Br Dent J 2003; 194: 613-618.

23. Cadenaro M, Antoniolli F, Sauro S et al. Degree of conversion and permeability of dental adhesives. Eur J Oral Sci 2005; 113: 525-530.

24. Yap A U, Soh M S, Han T T, Siow K S. Influence of curing lights and modes on crosslink density of dental composites. Oper Dent 2004; 29: 410-415.

25. Sasaki N, Okuda K, Kato T et al. Salivary bisphenol-A levels detected by ELISA after restoration with composite resin. J Mater Sci Mater Med 2005; 16: $297-300$

26. Joskow R, Barr D B, Barr J R, Calafat A M, Needham $L L$, Rubin $C$. Exposure to bisphenol A from bisglycidyl dimethacrylate-based dental sealants. J Am Dent Assoc 2006; 137: 353-362.

27. American Dental Association. 2005-06 survey of dental services rendered. Chicago: ADA, 2007.

28. Kovarik R E. Restoration of posterior teeth in clinical practice: evidence base for choosing amalgam versus composite. Dent Clin North Am 2009; 53: 71-76.

29. Sunnegårdh-Grönberg $K$, van Dijken J W. Funegård $U$, Lindberg A, Nilsson M. Selection of dental materials and longevity of replaced restorations in public dental health clinics in northern Sweden. J Dent 2009; 37: 673-678.

30. Bernardo M, Luis H, Martin M D et al. Survival and reasons for failure of amalgam versus composite posterior restorations placed in a randomized clinical trial. J Am Dent Assoc 2007; 138: 757-783.

31. Simecek J W, Diefenderfer K E, Cohen M E. An evaluation of replacement rates for posterior resinbased composite and amalgam restorations in U S
Navy and Marine Corps recruits. J Am Dent Assoc 2009; 140: 200-209.

32. Opdam N J Bronkhorst E M, Roeters J M Loomans $B$ A. A retrospective clinical study on longevity of posterior composite and amalgam restorations. Dent Mater 2007; 23: 2-8.

33. Opdam N J, Bronkhorst E M, Loomans B A Huysmans M C. 12-year survival of composite vs amalgam restorations. J Dent Res 2010; 89: 1063-1067.

34. Burke T, Earp D, Cheung S W. Effectiveness of light-curing units in vocational training practices. A project administered by the Research Committee of the Faculty of General Dental Practitioners (UK). Prim Dent Care 1997; 4: 91-94.

35. Mitton B A, Wilson N H. The use and maintenance of visible light activating units in general practice. Br Dent J 2001; 191: 82-86.

36. El-Mowafy O, El-Badrawy W, Lewis D W et al. Efficacy of halogen photopolymerization units in private dental offices in Toronto. J Can Dent Assoc 2005; 71: 587-592.

37. El-Mowafy O, El-Badrawy W, Lewis D W et al. Intensity of quartz-tungsten-halogen light-curing units used in private practice in Toronto. J Am Dent Assoc 2005; 136: 766-773.

38. Strydom C. Curing lights-the effects of clinical factors on intensity and polymerisation. SADJ 2002; 57: 181-186.

39. Santini A. Current status of visible light activation units and the curing of light-activated resin based composite materials. Dent Update 2010; 37: 214-227.

40. Malhotra N, Mala K. Light-curing considerations for resin-based composite materials: a review. Part I. Compend Contin Educ Dent 2010; 31: 498-505.

41. Malhotra N, Mala KJ. Light-curing considerations for resin-based composite materials: a review. Part II. Compend Contin Educ Dent 2010; 31: 584-588.

42. McFadzean R W, Gibson $E_{1}$ Newcombe R F, Nataraja $R$, Santini A. Resin-based composites and dentinebonding agents. Which, who and why? A study in the East of Scotland. Prim Dent Care 2009; 16: $59-66$.

43. Coupar M P, Bosnjak M. Internet surveys. In Wright J D, Marsden PV (eds) Handbook of survey research 2nd ed. Bingley, UK: Emerald Group Publishing Ltd, 2010. ISBN 978-1-84855-224-1.

44. Soh M S, Yap A U, Siow K S. The effectiveness of cure of LED and halogen curing lights at varying cavity depths. Oper Dent 2003; 28: 707-715.

45. Christensen G J. The light-curing mania. J Am Dent Assoc 2004; 135: 461-463.

46. Santos G B, Medeiros I S, Fellows C E, Muench A, Braga R R. Composite depth of cure obtained with QTH and LED units assessed by microhardness and micro-Raman spectroscopy. Oper Dent 2007. 32: 79-83.

47. Dunn W J, Bush A C. A comparison of polymerization by light-emitting diode and halogen-based light-curing units. J Am Dent Assoc 2002: 133: $335-341$

48. Shortall A C. How light source and product shade influence cure depth for a contemporary composite. J Oral Rehabil 2005; 32: 1-6.

49. Leonard D L, Charlton D G, Hilton T J. Effect of curing-tip diameter on the accuracy of dental radiometers. Oper Dent 1999; 24: 31-37.

50. Fan P L, Schumacher R M, Azzolin K, Geary R, Eichmiller F C. Curing-light intensity and depth of cure of resin-based composites tested according to international standards. J Am Dent Assoc 2002; 133: 429-434.

51. Dauvillier B S, Aarnts M P, Feilzer A J J. Developments in shrinkage control of adhesive restoratives. Esthet Dent 2000; 12: 291-299.

52. Malhotra N, Kundabala M, Shashirashmi A. Strategies to overcome polymerization shrinkage - materials and techniques. A review. Dent Update 2010; 37: 115-118.

53. Ueda M, Mine A, De Munck J, Hakogi T, Van Meerbeek B, Kuboki T. The effect of clinical experience on dentine bonding effectiveness: students versus trained dentists. J Oral Rehabil 2010; 37: 653-657. 